\title{
Orexin A induces autophagy in HCT-116 human colon cancer cells through the ERK signaling pathway
}

\author{
JING WEN $^{1}$, YUYAN ZHAO $^{1}$ and LEI GUO ${ }^{2}$ \\ Departments of ${ }^{1}$ Endocrinology and ${ }^{2}$ Orthopedic Surgery, First Affiliated Hospital, \\ China Medical University, Shenyang, Liaoning 110001, P.R. China
}

Received March 14, 2015; Accepted October 7, 2015

DOI: $10.3892 / \mathrm{ijmm} .2015 .2409$

\begin{abstract}
Orexins are a class of peptides which have a potent influence on a broad variety of cancer cells. Autophagy is closely associated with tumors; however, its function is not yet completely understood. In this study, we aimed to determine whether orexin A induces autophagy in HCT-116 human colon cancer cells and to elucidate the molecular mechanisms involved. For this purpose, HCT-116 cells were treated with orexin A, and cell viability was then measured by MTT assay, and apoptosis was determined by flow cytometry. The expression levels of autophagy-related proteins were measured by western blot analysis. Quantitative analysis of autophagy following acridine orange (AO) staining was performed using fluorescence microscopy, and cellular morphology was observed under a transmission electron microscope. In addition, the HCT-116 cells were treated with the extracellular signal-regulated kinase (ERK) inhibitor, U0126, or the autophagy inhibitor, chloroquine, in combination with orexin $\mathrm{A}$ in order to examine the activation of ERK. We found that orexin A significantly inhibited the viability of the HCT-116 cells. Both autophagy and apoptosis were activated during the orexin A-induced death of HCT-116 cells. When the HCT-116 cells were treated with orexin A for $24 \mathrm{~h}$, an accumulation of punctate microtubule-associated protein-1 light chain 3 (LC3) and an increase in LC3-II protein levels were also detected, indicating the activation of autophagy. Moreover, orexin A upregulated ERK phosphorylation; however, U0126 or chloroquine abrogated ERK phosphorylation and decreased autophagy, compared to treatment with orexin A alone.
\end{abstract}

Correspondence to: Dr Yuyan Zhao, Department of Endocrinology, First Affiliated Hospital, China Medical University, 155 Nanjing North Street, Shenyang, Liaoning 110001, P.R. China

E-mail: g572@sina.com

Dr Lei Guo, Department of Orthopedic Surgery, First Affiliated Hospital, China Medical University, 155 Nanjing North Street, Shenyang, Liaoning 110001, P.R. China

E-mail: 15241818899@163.com

Key words: orexin A, autophagy, extracellular signal-regulated kinase signaling pathway, HCT-116 human colon cancer cells
Therefore, our findings demonstratedm that orexin A induced autophagy through the ERK pathway in HCT-116 human colon cancer cells. The inhibition of autophagy may thus prove to be an effective strategy for enhancing the antitumor potential of orexin $\mathrm{A}$ as a treatment for colon cancer.

\section{Introduction}

Autophagy is a conserved eukaryotic cellular degradative process that is indispensible in cell homeostasis (1). Autophagy ameliorates cellular damage during stress conditions by eliminating damaged cellular machinery, aged organelles and unwanted macromolecules, and recycling them to produce essential nutrients and energy for reuse $(2,3)$. On the contrary, failure in any part of the autophagic machinery leads to the development of a variety of diseases, such as cancer (4-6), neurodegenerative diseases (7), heart diseases (8) and autoimmunity diseases (9). Consequently, the identification and/or development of autophagy-modulating compounds has become a new research goal for the treatment of these diseases.

The orexin peptides (orexin A and B) and their receptors (orexin receptor type 1 and 2 ) are involved in the regulation of numerous physiological processes, such as sleep/wakefulness (10), breathing (11), the reward system (12) and drug addiction $(12,13)$. Previous research has reported that orexin A markedly induces apoptosis, resulting in a reduction in cell growth in various cancer cell lines. In a previous study, orexin A promoted the apoptosis of HT29-D4 colon cancer cells, but not that of normal colonic epithelial cells (14). Upon treatment with orexins, Chinese hamster ovary $(\mathrm{CHO})$ cells transfected with orexin receptor type 1 (OX1R) cDNA underwent growth suppression and apoptosis, as did SK-N-MC neuroblastoma cells transfected with endogenous OX1R (14). In addition, it has been observed that OX1R receptors induced cell death via the p38 mitogen-activated protein kinase (MAPK), but independently of p53 and caspase activation in $\mathrm{CHO}$ cells (15). In another study, rat C6 glioma cells expressing both OX1R and orexin receptor type 2 (OX2R) were treated with orexin $\mathrm{A}$, which suppressed the growth of the cells through a caspase-dependent mechanism (16). However, programmed cell death is generally divided into apoptosis, autophagy and necrosis (17). Studies have mainly focused on the promotion of cell apoptosis by orexin A $(14,16)$; however, to date and to the best of our knowledge, no study has addressed the theory 
that orexin A can induce autophagy in cancer cells. Thus, in the present sudy, we investigated the effects of orexin A on autophagy in HCT-116 human colon cancer cells.

The extracellular signal-regulated kinase (ERK) controls various cellular processes, including autophagy. It has been shown that growth factor increases the interaction of the ERK cascade components with autophagy-related (ATG) proteins in both the cytosol and nucleus. ERK and its upstream kinase, MAPK/ERK kinase (MEK), localize to the extra-luminal face of autophagosomes, and lipidation of the autophagic protein, microtubule-associated protein-1 light chain 3 (LC3) upregulates ERK phosphorylation (18). The enhanced activity of ERK1/2 has been implicated in controlling the induction of autophagy in mammalian cancer cells (19). Based on these previous findings, in this study, we aimed to determine whether the MEK/ERK pathway plays a role in orexin A-induced autophagy.

In the present study, we hypothesized that a membrane-associated pathway is involved in orexin A-induced autophagy, and to prove this hypothesis, we used HCT-116 human colon cancer cells as a model. We observed that orexin A induced autophagy in the HCT-116 cells. Moreover, it was demonstrated that in the presence of an ERK inhibitor and an autophagy inhibitor, the orexin A-induced autophagy was inhibited, which indicated that orexin A induced autophagy through the ERK pathway. The findings of our study demonsrate a different mechanism responsible for the activation of the autophagic pathway induced by orexin $\mathrm{A}$.

\section{Materials and methods}

Reagents. Orexin A was purchased from Sigma-Aldrich (St. Louis, MO, USA). RPMI-1640 medium and fetal bovine serum (FBS) were purchased from Gibco-BRL (Grand Island, $\mathrm{NY}$, USA). Acridine orange (AO) and the autophagy inhibitor, chloroquine, were obtained from Sigma-Aldrich. The ERK inhibitor, U0126, was purchased from Beyotime Biotechnology (Jiangsu, China). Anti-actin (\#sc-1616) and anti-ERK (\#sc-292838) antibodies were purchased from Santa Cruz Biotechnology, Inc. (Santa Cruz, CA, USA). Anti-Beclin-1 antibody (\#B6061) was purchased from Sigma-Aldrich. Anti-LC3 (\#L7543) and anti-p-ERK (\#4370s) antibodies were purchased from Cell Signaling Technology, Inc. (Danvers, MA, USA).

Cell culture. HCT-116 human colon cancer cells were obtained from the American Type Culture Collection (ATCC, Manassas, VA, USA) and were maintained in RPMI-1640 medium supplemented with FBS (10\% w/v), L-glutamine (2 mM), penicillin $(50 \mu \mathrm{g} / \mathrm{ml})$ and streptomycin $(100 \mu \mathrm{g} / \mathrm{ml})$ (Beyotime Biotechnology). The cells were incubated in a humidified atmosphere containing $5 \%$ carbon dioxide $\left(\mathrm{CO}_{2}\right)$ at $37^{\circ} \mathrm{C}$. The cells were subcultured every 2-3 days to maintain the logarithmic phase of their growth.

Cell viability. The HCT-116 cells were seeded ( $2 \times 10^{3}$ cells/well) on a 96-well plate and cultured for $24 \mathrm{~h}$. Following incubation in serum-free RPMI-1640 medium supplemented with with orexin $\mathrm{A}\left(0,10^{-9}, 10^{-8}\right.$ and $\left.10^{-7} \mathrm{M}\right)$ for $24 \mathrm{~h}$, thiazolyl blue tetrazolium blue (MTT) solution $(0.5 \mathrm{mg} / \mathrm{ml})$ was added (Sigma-Aldrich). After $3 \mathrm{~h}$, the culture medium was removed and formazan crystals that had formed were dissolved using
$100 \mu 1$ dimethyl sulfoxide (Merck KGaA,Darmstadt, Germany). Optical density was measured using a plate reader (SpectraMax Plus 384 Microplate Reader; Molecular Devices, Ismaning, Germany) at 570 and $650 \mathrm{~nm}$ (reference wave/length).

Annexin V/propidium iodide (PI) assays for the measurement of apoptosis. The number of apoptotic cells was quantified using the Annexin V/PI Apoptosis Detection kit and the cells were evaluated to determine apoptosis using a BD Accuri ${ }^{\mathrm{TM}} \mathrm{C6}$ Flow Cytometer according to the manufacturer's instructions (BD Pharmingen, San Diego, CA, USA). The cells were treated with various concentrations of orexin $\mathrm{A}$ in serum-free medium for $48 \mathrm{~h}$. The cells $\left(1 \times 10^{5}\right)$ were then washed twice with phosphate-buffered saline (PBS) and stained with Annexin V-fluorescein isothiocyanate (FITC; $5 \mu \mathrm{l}$ ) and PI $(10 \mu \mathrm{l})$ in $500 \mu \mathrm{l}$ binding buffer for $15 \mathrm{~min}$ at room temperature in the dark. The rate of apoptosis was determined by counting the number of cells stained by FITC-labeled Annexin V by fluorescence-activated cell sorting (FACS) analysis. The early apoptotic cells were identified as PI-negative and FITC-Annexin V-positive; cells that were in late apoptosis or already dead were PI- as well as FITC-Annexin V-positive.

Transmission electron microscopy. The cells were treated and collected by trypsinization, fixed with $2.5 \%$ phosphate-buffered glutaraldehyde, and post-fixed in $1 \%$ phosphate-buffered osmium tetroxide. The cells were embedded, sectioned, double stained with uranyl acetate and lead citrate, and analyzed using a JEM-1200EX transmission electron microscope (TEM; JEOL, Tokyo, Japan).

AO staining. AO $(0.1 \mathrm{mg} / \mathrm{ml})$ was added to the cells following treatment with various concentrations of orexin $\mathrm{A}$ $\left(0,10^{-9}, 10^{-8}\right.$ and $\left.10^{-7} \mathrm{M}\right)$ for $24 \mathrm{~h}$, or to the untreated controls cells for a period of $20 \mathrm{~min}$ in the dark at $37^{\circ} \mathrm{C}$. The cells were washed twice with PBS. The cells were then examined under a fluorescence microscope (Olympus Optical Co., Hamburg, Germany).

Flow cytometric quantification of acidic vesicular organelles (AVOs). For the quantification of AVOs, flow cytometry was used following the staining of the cells with AO. AO is a weak base that accumulates in the acidic spaces and imparts bright red fluorescence [punctate staining (dots)] in the cytoplasm, which is detected under a fluorescence microscope. The intensity of the red fluorescence is proportional to the degree of acidity. Thus, the formation of AVOs can be quantified. Briefly, the HCT-116 cells were harvested following treatment with various concentrations of orexin $\mathrm{A}$ $\left(0,10^{-9}, 10^{-8}\right.$ and $\left.10^{-7} \mathrm{M}\right)$ for $24 \mathrm{~h}$. The cell pellet was collected in an Eppendorf tube, and the cells were resuspended in PBS $(1 \mathrm{ml})$. The staining of the cells was performed with AO $(0.1 \mathrm{mg} / \mathrm{ml})$ for $20 \mathrm{~min}$ in the dark at $37^{\circ} \mathrm{C}$. The cells were centrifuged at $1,000 \mathrm{rpm}$ for $5 \mathrm{~min}$; the cell pellet was then rinsed twice with PBS, resuspended in PBS (500 $\mu \mathrm{l})$, and analyzed by flow cytometry using the PI staining assay. Cell death was determined by PI staining.

Protein preparations and western blot analysis. The HCT-116 cells were washed with cold PBS and harvested 

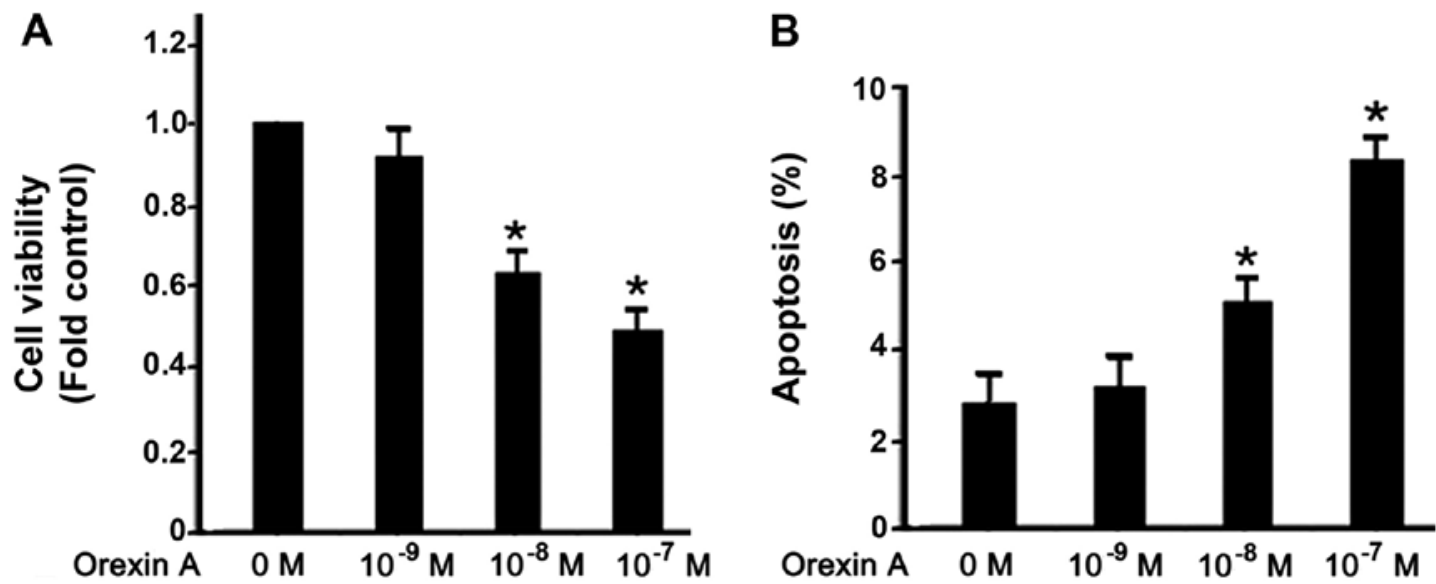

Figure 1. Effects of orexin A on the viability and apoptosis of HCT-116 cells. HCT-116 cells were treated with orexin A $\left(0,10^{-9}, 10^{-8}\right.$ and $\left.10^{-7} \mathrm{M}\right)$ for $24 \mathrm{~h}$. (A) Cell viability was determined by MTT assay. (B) Cell apoptosis was determined by flow cytometry followed by Annexin V staining. Data are presented as the means \pm SEM based on triplicate determinations from a representative experiment. Asterisks indicate significant differences as compared to the unteated control ( $\mathrm{P}<0.05)$.

in radioimmunoprecipitation assay buffer (Beyotime Biotechnology) containing protease inhibitors, namely phenylmethylsulfonyl fluoride (Beijing, Jiangsu, China) and phosphatase inhibitors (Nanjing KeyGen Biotech Co., Ltd., Nanjing, China). The cell lysates were incubated on ice for $30 \mathrm{~min}$, and were then collected and centrifuged at $12,000 \mathrm{x} \mathrm{g}$ for $10 \mathrm{~min}$ at $4^{\circ} \mathrm{C}$. The supernatants were collected and mixed with $5 \mathrm{X}$ loading buffer, and were denatured by boiling for $10 \mathrm{~min}$. The samples were separated by sodium dodecyl sulfate-polyacrylamide gel electrophoresis (SDS-PAGE) and transferred onto polyvinylidene fluoride membranes at $60 \mathrm{~V}$ for $2.5 \mathrm{~h}$ in a transfer buffer containing Tris $(20 \mathrm{mM})$ (bioWORLD, Dublin, OH, USA), $150 \mathrm{mM}$ glycine (Beijing Solarbio Science \& Technology Co., Ltd., Beijing, China) and methanol (20\%) (Liaoning Xinxing Chemical Group Co., Ltd., Liaoning, China). The membranes were incubated in non-fat dry milk for $120 \mathrm{~min}$ at room temperature, and were washed thrice with Tris-buffered saline with Tween 20 (TBST) for $30 \mathrm{~min}$. The membranes were incubated with primary antibodies in TBST overnight at $4^{\circ} \mathrm{C}$. The membranes were then washed and incubated with horseradish peroxidase-conjugated anti-species secondary antibody (A0208; Beyotime Biotechnology) for $1.5 \mathrm{~h}$ at room temperature, and were washed thrice with TBST for $30 \mathrm{~min}$. Proteins were visualized using the BeyoECL plus kit (Beyotime Biotechnology).

Statistical analysis. Data are expressed as the means \pm standard error of the mean (SEM), and the differences between the means were analyzed by one-way analysis of variance (ANOVA). A P-value $<0.05$ was considered to indicate a statistically significant difference. Statistical analysis was performed using the Statistical Package for the Social Sciences (SPSS) 15.0 software package (SPSS, Inc., Chicago, IL, USA).

\section{Results}

Orexin A inhibits cell viability and induces apoptosis. The HCT-116 cells were treated with various concentrations of orexin A $\left(0,10^{-7}, 10^{-8}\right.$ and $\left.10^{-9} \mathrm{M}\right)$. The cells were serumstarved for $24 \mathrm{~h}$ prior to exposure to the test compounds in order to avoid interaction with growth factors and other mediators present in the serum. The results from the MTT assay revealed that orexin $\mathrm{A}$ inhibited cell growth in a dose-dependent manner. Treatment with orexin A at the concentrations of $10^{-8}$ and $10^{-7} \mathrm{M}$ resulted in a significant decrease in the viability of the HCT-116 cells as compared to the untreated control $(\mathrm{P}<0.05$; Fig. $1 \mathrm{~A})$. The results of flow cytometry indicated a significant increase in apoptosis in the cells treated with orexin A for $24 \mathrm{~h}$. Thus, the present study demonstrated that treatment with orexin $\mathrm{A}\left(10^{-7} \mathrm{M}\right)$ increased the cell apoptotic rate by 1.5 -fold, as compared to the untreated control $(\mathrm{P}<0.05$; Fig. 1B). These findings indicate that orexin $\mathrm{A}$ inhibits HCT-116 cell viability by inducing apoptosis.

Formation of autophagic vacuoles and AVOs in HCT-116 human colon cancer cells. To further elucidate the anticancer effects of orexin A, we examined other cellular responses associated with cell death following treatment of the cells with orexin A. In contrast to the untreated control group, numerous microscopic vacuoles were observed in the HCT-116 cells treated with orexin A $\left(10^{-7} \mathrm{M}\right)$ (Fig. 2). Since the formation of double-membrane autophagic vacuoles is a characteristic of autophagy, we focused on examining the ultrastructural details of the vacuoles using a TEM. As shown in Fig. 2A, various membrane-associated vacuoles were observed in the cytoplasm of the HCT-116 cells treated with orexin A. To further characterize the membrane-associated vacuoles, AO staining was used to analyze the formation of AVOs, which is a characteristic of autophagy. Orexin A induced the formation of orange AVOs in a dose-dependent manner in the HCT-116 cells, whereas the cells in the untreated control group primarily exhibited green fluorescence, indicating a lack of AVOs (Fig. 3A-D). The orexin A-induced formation of AVOs was quantified by flow cytometry after staining the cells with AO. The results from the flow cytometry demonstrated a dose-dependent increase in the percentage of AVOs from 0.8 to $21 \%$ (Fig. 3E-H).

Orexin A induces LC3-II accumulation. We demonstrated that orexin A induced autophagy in HCT-116 cells, an obser- 

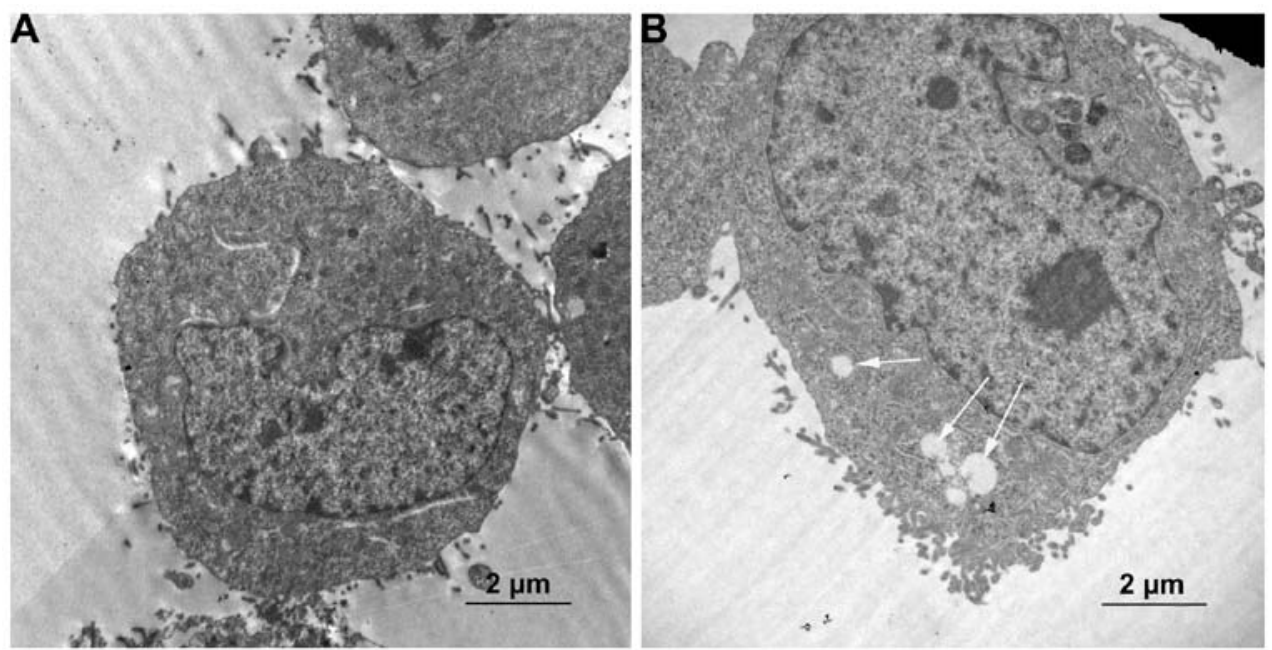

Figure 2. Orexin A induces the formation of autophagic vacuoles in HCT-116 cells. (A) Untreated HCT-116 cells exhibited normal morphology of the cytoplasm, cell organelles and nuclei. (B) Transmission electron microscopy images indicating autophagic vacuoles in the HCT-116 cells treated with $10^{-7} \mathrm{M}$ orexin A for $24 \mathrm{~h}$. Arrows indicate autophagic vacuoles.

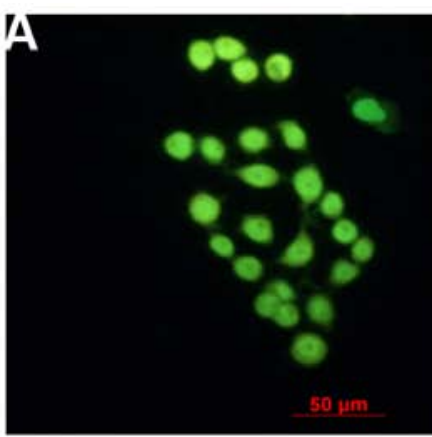

$\mathbf{E}$

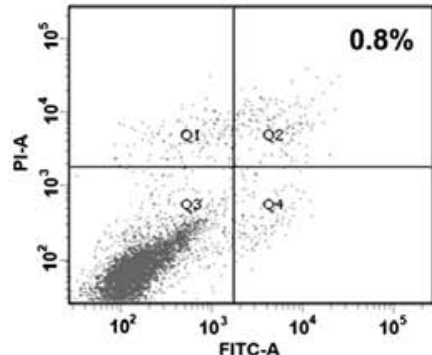

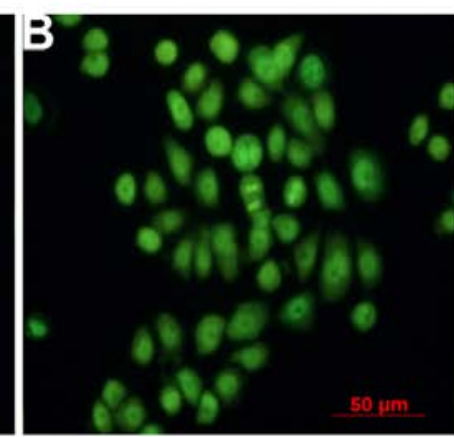

$\mathbf{F}$

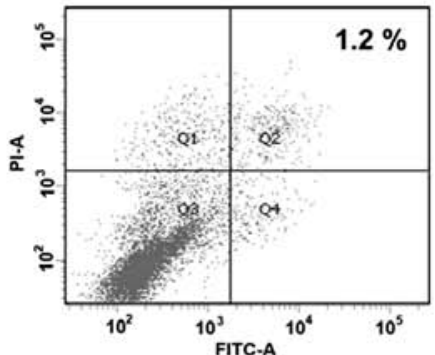

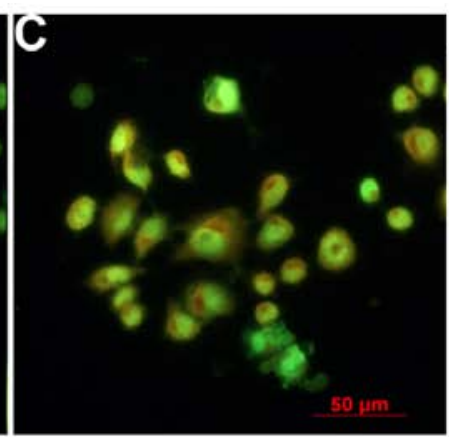

G

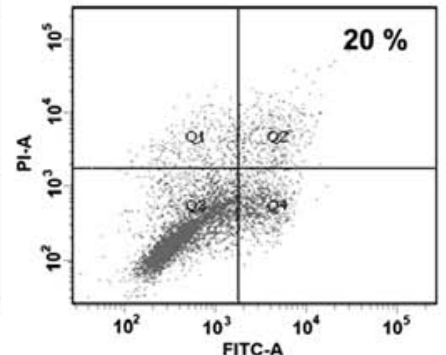

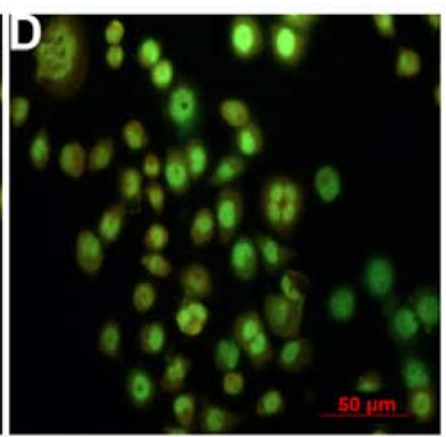

H

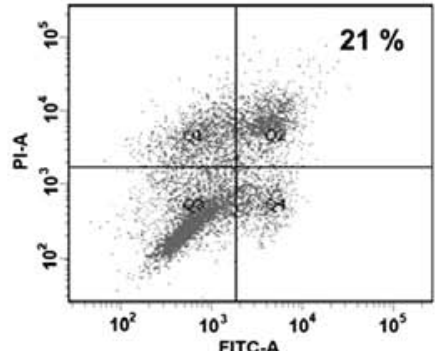

Figure 3. Orexin A induces the formation of autophagic vacuoles and acidic vesicular organelles (AVOs) in HCT-116 cells. (A-D) Representative images of acridine orange (AO) staining of HCT-116 cells following treatment with various concentrations [(A) 0 , (B) $10^{-9}$, (C) $10^{-8}$ or (D) $\left.10^{-7} \mathrm{M}\right]$ of orexin A for $24 \mathrm{~h}$. For AO staining, red color intensity indicates AVOs (representing autophagolysosomes). HCT-116 cells were treated with orexin A and were stained with AO. (E-H) Cell autophagy was analyzed by the quantification of AVOs with AO staining by flow cytometry. HCT-116 cells were treated with various concentrations $\left[(\mathrm{E}) 0,(\mathrm{~F}) 10^{-9},(\mathrm{G}) 10^{-8}\right.$ or $\left.(\mathrm{H}) 10^{-7} \mathrm{M}\right]$ of orexin $\mathrm{A}$ for $24 \mathrm{~h}$. Representative data from one of three independent experiments are shown.

vation which was based on the ultrastructural changes in the cells as observed by a TEM and the visualization of acridine orange-labeled autophagic vacuoles under a fluorescence microscope. Thus, we further examined the expression levels of LC3, which exists in cells in two forms: LC3-I and LC3-II. LC3-I resides in the cytoplasm and conjugates with phosphatidylethanolamine to form LC3-II, which is closely associated with autophagosome membranes and serves as a reliable marker for autophagy. Western blot analysis of the proteins obtained from the orexin A-treated cells revealed the pres- ence of two bands. Weak bands corresponding to LC3-I and LC3-II were observed in the untreated cells. When the cells were treated with orexin A $\left(10^{-7} \mathrm{M}\right)$, the expression levels of LC3-II were significantly increased in a time-dependent manner (Fig. 4A). The exposure of the HCT-116 cells to orexin A for $24 \mathrm{~h}$ also resulted in a concentration-dependent increase in the LC3-II protein levels (Fig. 4B).

Orexin A upregulates the expression of Beclin-1 in the HCT-116 cells. Based on the above-mentioned results, we speculated that 
A

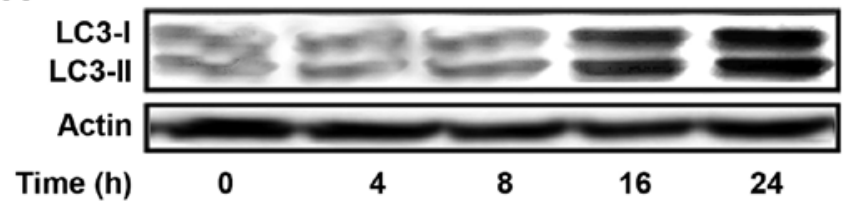

B

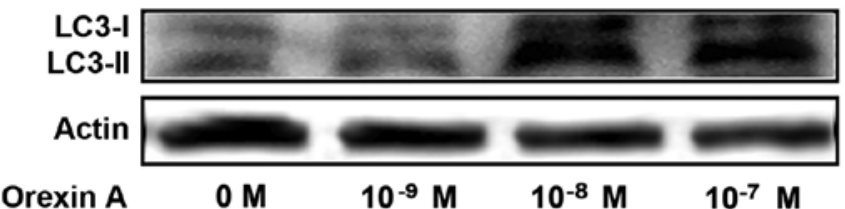

Figure 4. Orexin A induces LC3-II accumulation in HCT-116 cells. (A) Western blot analysis of LC3 expression in HCT-116 cells treated with $10^{-7} \mathrm{M}$ orexin A for the indicated periods of time. (B) HCT-116 cells were treated with various concentrations of orexin A for $24 \mathrm{~h}$. The protein expression of LC3 was measured by western blot analysis. Actin was used as a loading control. All data are representative of three independent experiments.

A

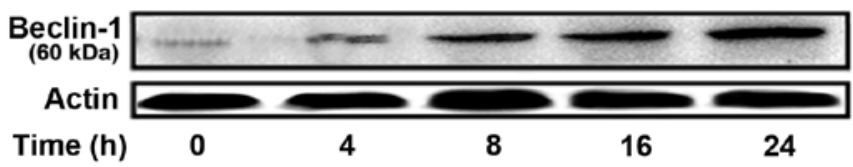

B

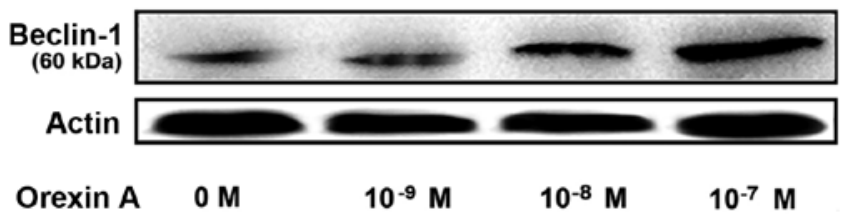

Figure 5. Orexin A activates the autophagy-related gene Beclin-1 in HCT-116 cells. HCT-116 cells were treated with various concentrations of orexin A for the indicated periods of time. The protein activation of Beclin-1 ( 60 kDa) was normalized against the total protein activation. Actin was used as an internal control. Data are presented as the means \pm SEM based on triplicate determinations from a representative experiment.

orexin A would induce HCT-116 cell death through the apoptosis and autophagic pathways simultaneously. To gain better insight into the molecular mechanisms underlying the autophagy and apoptosis induced by orexin A, the expression levels of Beclin-1, which plays a key role in autophagy in HCT-116 cells treated with orexin A, were measured by western blot analysis. As shown in Fig. 5, orexin A upregulated the expression of Beclin-1 in a dose- and time-dependent manner. These findings indicate that the upregulation of Beclin-1 may contribute to the induction of autophagy caused by orexin A.

Orexin A induces autophagy in HCT-116 cells through the ERK signaling pathway. In order to confirm the involvement of the ERK signaling pathway in orexin A-indcued autophagy in HCT-116 cells, the protein expression levels of LC3 and Beclin-1 were measured by western blot analysis. The results revealed that treatment with $10^{-7} \mathrm{M}$ orexin A significantly increased the expression levels of LC3-II and Beclin-1 (Fig. 6).
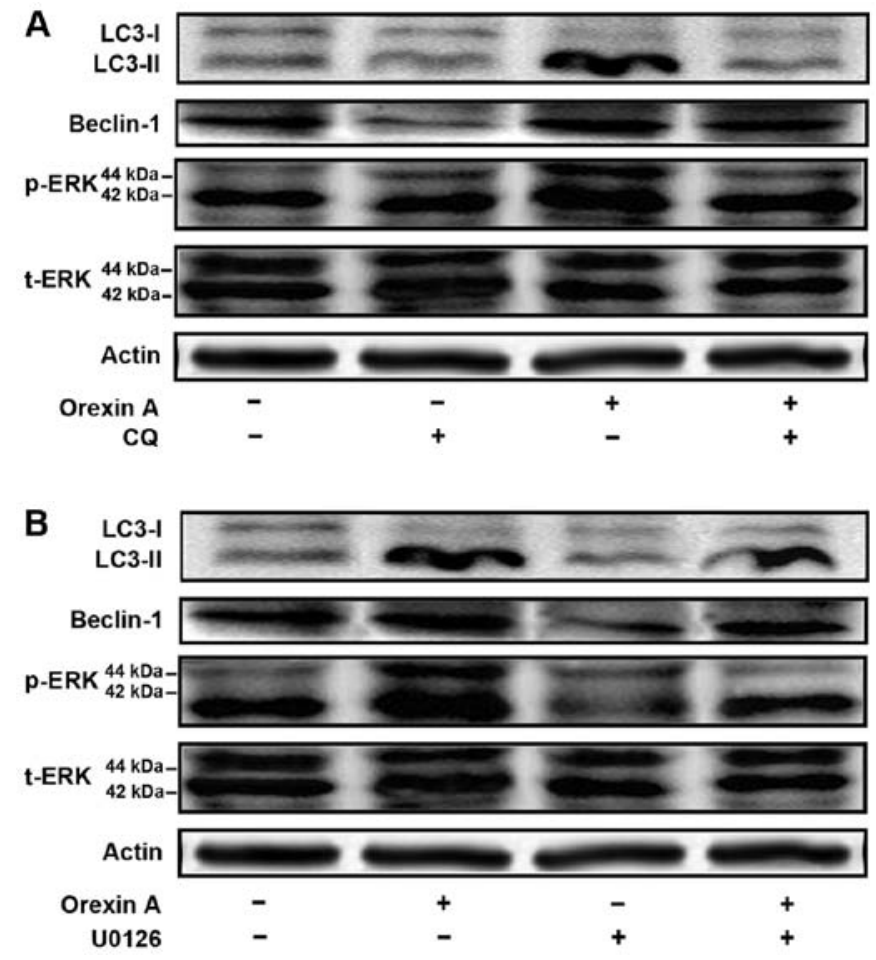

Figure 6. Orexin A induces autophagy in HCT-116 cells through the activation of the ERK signaling pathway. (A) Representative blots of p-ERK, ERK1/2, Beclin-1 and LC3 protein expression following treatment of the cells with either $10^{-7} \mathrm{M}$ orexin A or $20 \mu \mathrm{mol} / 1$ chloroquine (CQ) for $24 \mathrm{~h}$. Cell lysates were analyzed by western blot analysis using anti-p ERK, ERK1/2, Beclin-1 and LC3 antibodies. (B) Cells were exposed to orexin A at concentrations of 0 and $10^{-7} \mathrm{M}$ for $24 \mathrm{~h}$ in the presence or absence of the ERK-specific inhibitor, U0126 $\left(10^{-5} \mathrm{M}\right)$. Cell lysates were analyzed by western blot analysis using anti-pERK, ERK1/2, Beclin-1 and LC3 antibodies. Data shown represent the means \pm standard error of the mean (SEM) of three independent experiments.

However, this effect was blocked by treatment wiht $10^{-5} \mathrm{M}$ of the ERK antagonist, U0126, or with $20 \mu \mathrm{mol} / 1$ chloroquine (autophagy inhibitor) (Fig. 6). Moreover, the expression levels of LC3-II and Beclin-1 were not significantly altered when the cells were treated with the ERK antagonist, U0126, or chloroquine without orexin A treatment (Fig. 6). These data suggest that ERK participates in the autophagy of HCT-116 cells induced by orexin A.

It is well known that the ERK signaling pathway is involved in cell autophagy and apoptotic signaling; therefore, the we also wished to investigate whether the treatment of HCT-116 cells with orexin A induces the activation of ERK. Our results reavealed a 1.5 -fold increase in $\mathrm{p}$-ERK protein expression in the HCT-116 cells treated with $10^{-7} \mathrm{M}$ orexin A compared to the untreated control cells (Fig. 6). However, the total ERK (t-ERK) levels remained unaffected by the aforementioned treatment. Moreover, treatment with $10^{-5} \mathrm{M}$ of the ERK antagonist, U0126, or with $20 \mu \mathrm{mol} / 1$ chloroquine (autophagy inhibitor) abolished the relative increase in ERK activation in response to orexin A independently (Fig. 6).

\section{Discussion}

It has previously been demonstrated that orexin A is involved in a wide range of biological activities (10-13). In particular, 
orexin A has been reported to exert anti-proliferative and apoptotic effects on cancer cells $(20,21)$. Programmed cell death is generally divided into apoptosis, autophagy and necrosis. Previous studies have focused on the promotion of cell apoptosis by orexin A $(14,16)$, and a few have reported on the promotion of autophagy by orexin A. To the best of our knowlege, there is no study available to date addressing the theory that orexin A induces autophagy in cancer cells. In this study, we investigated the effects of orexin A on autophagy in HCT-116 human colon cancer cells.

Autophagy can be induced under various circumstances, including aging, nutrient deprivation, as well as chemical therapy and radiation cancer therapy $(3,22)$. Autophagy is a process of catabolism through which macromolecules and organelles are recycled using lysosomal degradation machinery $(3,23)$. Autophagy begins with the formation of double-membraned vesicles known as autophagosomes, which undergo acidification after maturation and subsequently fuse with lysosomes to form autophagolysosomes (24). Autophagy likely plays different roles in the occurrence and progression of cancer, while it also potentially promotes or inhibits cell proliferation at different stages of tumor growth (25). For example, autophagy plays a protective role in tumor cells via the degradation of organelles under conditions of nutritional deficiency. Conversely, autophagy can also inhibit tumor growth via Beclin-1, UV radiation resistance associated gene (UVRAG), Bif and ATG proteins (26). In the present study, we observed that orexin A inhibited the proliferation and induced the apoptosis of HCT-116 cells. Moreover, treatment of the cells with orexin A induced changes to the cells which are characteristic of autophagy, such as the formation of cytoplasmic autophagic vacuoles and autophagosomes. It was evident that AVOs formed following the exposure of the cells to orexin A, which was shown by AO staining. The formation of autophagosomes was further confirmed by transmission electron microscopy. Additionally, the conversion of LC3-I to LC3-II induced by orexin A was also shown by western blot analysis, and we also noted that LC3 expression increased in a dose- and time-dependent manner following treatment with orexin A. These specific changes of LC3 have been characterized as an autophagosomal marker in mammalian autophagy. Our results demonstrated that orexin A induced autophagy in HCT-116 human colon cancer cells .

We further examined the protein expression levels of Beclin-1 in the HCT-116 cells. Beclin-1 is a part of the class III phosphatidylinositol 3-kinase (PI3K) complex, which is essential for the initiation of the early stages of autophagy. Beclin-1 expression is commonly decreased or absent in various cancer cells, such as human breast carcinoma, ovarian cancer, brain tumors, cervical cell carcinoma and gastric cancer (27-31). These findings demonstrate that Beclin-1 is a critical component of mammalian autophagy. In the present study, treatment of the HCT-116 cells with orexin A increased the expression of Beclin-1 in a dose-dependent manner, indicating that Beclin-1 is involved in orexin A-induced autophagy and plays an important role in orexin A-mediated anticancer activities.

ERK is a versatile protein kinase that regulates a number of cellular functions. It is considered that the magnitude and duration of ERK1/2 activity determine its cellular function (32). It has also been reported that the activation of the
ERK1/2 pathway increases the expression of autophagic genes, which can lead to an increase in the autophagic flux $(33,34)$. An increase in p-ERK 1/2 and ATG protein LC3-II expression has also been observed in human glioma cells treated with interferon $\beta$ (IFN- $\beta$ ). The autophagy induced by IFN- $\beta$ was suppressed when $\mathrm{p}$-ERK $1 / 2$ was inhibited by treatment with U0126 (35). U0126 is a chemically synthesized organic compound, which inhibits the catalytic activity of the activating enzyme through non-competitive binding to MEK, thereby decreasomg the phosphorylation of ERK1/2 (36,37). Certain antitumor drugs induce autophagy and activate the ERK1/2 signaling pathways in human lung cancer cells (38). In the present study, we found that orexin A significantly enhanced the phosphorylation of ERK, and we also noted that the p-ERK inhibitor, U0126, reduced the orexin A-induced increase in LC3-II expression. To further investigate the effects of orexin A on cell autophagy through the ERK pathway, we used the autophagy inhibitor, chloroquine as a reference. Chloroquine blocks the process of autophagy by blocking autophagic bodies fused with lysosomes, and thus cells cannot be provided with raw materials or energy (39). Our results revealed that the ERK inhibitor and autophagy inhibitor significantly inhibited the promoting effects of orexin A on autophagy, indicating that orexin A induced autophagy through the ERK pathway.

In conclusion, in the present study, we explored the antitumor effects and the underlying mechanisms of action of orexin A on colon cancer cells. Our data lay the experimental foundation for the better development and clinical application of orexin A.

\section{Acknowledgements}

The authors would like to thank The China Medical University Affiliated Hospital Laboratory Center for kindly providing the equipment. This study was supported by the National Natural Science Foundation of China (grant nos. 81470998, 81071460 and 81271996) and the Natural Science Foundation of Liaoning Province (grant no. 201202292).

\section{References}

1. Mizushima N, Levine B, Cuervo AM and Klionsky DJ: Autophagy fights disease through cellular self-digestion. Nature 451: 1069-1075, 2008.

2. Levine B, Mizushima N and Virgin HW: Autophagy in immunity and inflammation. Nature 469: 323-335, 2011.

3. Choi AM, Ryter SW and Levine B: Autophagy in human health and disease. N Engl J Med 368: 1845-1846, 2013.

4. Koneri K, Goi T, Hirono Y, Katayama K and Yamaguchi A: Beclin 1 gene inhibits tumor growth in colon cancer cell lines. Anticancer Res 27: 1453-1457, 2007.

5. Mathew R, Karp CM, Beaudoin B, Vuong N, Chen G, Chen HY, Bray K, Reddy A, Bhanot G, Gelinas C, et al: Autophagy suppresses tumorigenesis through elimination of p62. Cell 137: 1062-1075, 2009.

6. Mathew R, Kongara S, Beaudoin B, Karp CM, Bray K, Degenhardt K, Chen G, Jin S and White E: Autophagy suppresses tumor progression by limiting chromosomal instability. Genes Dev 21: 1367-1381, 2007.

7. Wong E and Cuervo AM: Autophagy gone awry in neurodegenerative diseases. Nat Neurosci 13: 805-811, 2010.

8. Xie M, Morales CR, Lavandero S and Hill JA: Tuning flux: autophagy as a target of heart disease therapy. Curr Opin Cardiol 26: 216-222, 2011.

9. Taneike M, Yamaguchi O, Nakai A, Hikoso S, Takeda T, Mizote I, Oka T, Tamai T, Oyabu J, Murakawa T, et al: Inhibition of autophagy in the heart induces age-related cardiomyopathy. Autophagy 6: 600-606, 2010. 
10. Sakurai T, Mieda M and Tsujino N: The orexin system: roles in sleep/wake regulation. Ann N Y Acad Sci 1200: 149-161, 2010.

11. Gestreau C, Bévengut $M$ and Dutschmann M: The dual role of the orexin/hypocretin system in modulating wakefulness and respiratory drive. Curr Opin Pulm Med 14: 512-518, 2008.

12. Aston-Jones G, Smith RJ, Sartor GC, Moorman DE, Massi L, Tahsili-Fahadan P and Richardson KA: Lateral hypothalamic orexin/hypocretin neurons: a role in reward-seeking and addiction. Brain Res 1314: 74-90, 2010.

13. Kodadek T and Cai D: Chemistry and biology of orexin signaling. Mol Biosyst 6: 1366-1375, 2010.

14. Rouet-Benzineb P, Rouyer-Fessard C, Jarry A, Avondo V, Pouzet C, Yanagisawa M, Laboisse C, Laburthe $\mathrm{M}$ and Voisin T: Orexins acting at native $\mathrm{OX}(1)$ receptor in colon cancer and neuroblastoma cells or at recombinant OX(1) receptor suppress cell growth by inducing apoptosis. J Biol Chem 279: 45875-45886, 2004.

15. Ammoun S, Lindholm D, Wootz H, Akerman KE and Kukkonen JP: G-protein-coupled OX1 orexin/hcrtr-1 hypocretin receptors induce caspase-dependent and -independent cell death through p38 mitogen-/stress-activated protein kinase. J Biol Chem 281: 834-842, 2006.

16. Biegańska K, Sokołowska P, Jöhren O and Zawilska JB Orexin A suppresses the growth of rat C6 glioma cells via a caspase-dependent mechanism. J Mol Neurosci 48: 706-712, 2012.

17. Quan W, Lim YM and Lee MS: Role of autophagy in diabetes and endoplasmic reticulum stress of pancreatic $\beta$-cells. Exp Mol Med 44: 81-88, 2012.

18. Martinez-Lopez N, Athonvarangkul D, Mishall P, Sahu S and Singh R: Autophagy proteins regulate ERK phosphorylation. Nat Commun 4: 2799, 2013.

19. Ellington AA, Berhow MA and Singletary KW: Inhibition of Akt signaling and enhanced ERK1/2 activity are involved in induction of macroautophagy by triterpenoid B-group soyasaponins in colon cancer cells. Carcinogenesis 27: 298-306, 2006.

20. Alexandre D, Hautot C, Mehio M, Jeandel L, Courel M, Voisin T, Couvineau A, Gobet F, Leprince J, Pfister C, et al: The orexin type 1 receptor is overexpressed in advanced prostate cancer with a neuroendocrine differentiation, and mediates apoptosis. Eur J Cancer 50: 2126-2133, 2014.

21. Esmaeili-Mahani S, Vazifekhah S, Pasban-Aliabadi H, Abbasnejad M and Sheibani V: Protective effect of orexin-A on 6-hydroxydopamine-induced neurotoxicity in SH-SY5Y human dopaminergic neuroblastoma cells. Neurochem Int 63: 719-725, 2013.

22. Awan MU and Deng Y: Role of autophagy and its significance in cellular homeostasis. Appl Microbiol Biotechnol 98: 5319-5328, 2014.

23. Mizushima N and Komatsu M: Autophagy: renovation of cells and tissues. Cell 147: 728-741, 2011.

24. Maiuri MC, Tasdemir E, Criollo A, Morselli E, Vicencio JM, Carnuccio R and Kroemer G: Control of autophagy by oncogenes and tumor suppressor genes. Cell Death Differ 16: 87-93, 2009.
25. White E: Deconvoluting the context-dependent role for autophagy in cancer. Nat Rev Cancer 12: 401-410, 2012.

26. Helgason GV, Holyoake TL and Ryan KM: Role of autophagy in cancer prevention, development and therapy. Essays Biochem 55: 133-151, 2013.

27. Liang XH, Jackson S, Seaman M, Brown K, Kempkes B, Hibshoosh $\mathrm{H}$ and Levine B: Induction of autophagy and inhibition of tumorigenesis by beclin 1. Nature 402: 672-676, 1999.

28. Aita VM, Liang XH, Murty VV, Pincus DL, Yu W, Cayanis E, Kalachikov S, Gilliam TC and Levine B: Cloning and genomic organization of beclin 1, a candidate tumor suppressor gene on chromosome 17q21. Genomics 59: 59-65, 1999.

29. Miracco C, Cosci E, Oliveri G, Luzi P, Pacenti L, Monciatti I, Mannucci S, De Nisi MC, Toscano M, Malagnino V, et al: Protein and mRNA expression of autophagy gene Beclin 1 in human brain tumours. Int J Oncol 30: 429-436, 2007.

30. Wang ZH, Xu L, Duan ZL, Zeng LQ, Yan NH and Peng ZL: Beclin 1-mediated macroautophagy involves regulation of caspase-9 expression in cervical cancer HeLa cells. Gynecol Oncol 107: 107-113, 2007.

31. Furuya D, Tsuji N, Yagihashi A and Watanabe N: Beclin 1 augmented cis-diamminedichloroplatinum induced apoptosis via enhancing caspase-9 activity. Exp Cell Res 307: 26-40, 2005.

32. Subramaniam $S$ and Unsicker K: ERK and cell death: ERK1/2 in neuronal death. FEBS J 277: 22-29, 2010.

33. Dai JP, Zhao XF, Zeng J, Wan QY, Yang JC, Li WZ, Chen XX, Wang GF and Li KS: Drug screening for autophagy inhibitors based on the dissociation of Beclin1-Bcl2 complex using BiFC technique and mechanism of eugenol on anti-influenza A virus activity. PLoS One 8: e61026, 2013.

34. Niso-Santano M, Criollo A, Malik SA, Michaud M, Morselli E, Mariño G, Lachkar S, Galluzzi L, Maiuri MC and Kroemer G: Direct molecular interactions between Beclin 1 and the canonical NFKB activation pathway. Autophagy 8: 268-270, 2012.

35. Li Y, Zhu H, Zeng X, Fan J, Qian X, Wang S, Wang Z, Sun Y, Wang X, Wang W and Ju D: Suppression of autophagy enhanced growth inhibition and apoptosis of interferon- $\beta$ in human glioma cells. Mol Neurobiol 47: 1000-1010, 2013.

36. Favata MF1, Horiuchi KY, Manos EJ, Daulerio AJ, Stradley DA, Feeser WS, Van Dyk DE, Pitts WJ, Earl RA, Hobbs F, et al: Identification of a novel inhibitor of mitogen-activated protein kinase kinase. J Biol Chem 273: 18623-18632, 1998.

37. Ji RR, Befort K, Brenner GJ and Woolf CJ: ERK MAP kinase activation in superficial spinal cord neurons induces prodynorphin and NK-1 upregulation and contributes to persistent inflammatory pain hypersensitivity. J Neurosci 22: 478-485, 2002.

38. Hsieh MJ, Tsai TL, Hsieh YS, Wang CJ and Chiou HL: Dioscin-induced autophagy mitigates cell apoptosis through modulation of PI3K/Akt and ERK and JNK signaling pathways in human lung cancer cell lines. Arch Toxicol 87: 1927-1937, 2013.

39. Rubinsztein DC, Gestwicki JE, Murphy LO and Klionsky DJ: Potential therapeutic applications of autophagy. Nat Rev Drug Discov 6: 304-312, 2007. 